\section{CME lieber mit Sponsoren als mit eigenem Geld?}

Das Unbehagen ist verbreitet, wenn Organisation und Referenten ärztlicher Fortbildungsveranstaltungen von der Industrie unterstützt werden. Doch Ärzte wollen auf diese Hilfe nicht zulasten eigener Kosten verzichten - zumindest in den USA.

$\mathrm{n}$ den USA wurden Teilnehmer eintägiger Fortbildungsveranstaltungen um ihre Meinung gebeten. In fünf Großstädten wurden 1.347 Fragebögen ausgegeben, 770 (57\%) kamen ausgefüllt zurück. Diese stammten zu $69 \%$ von Ärzten, die schon seit mindestens zehn Jahren in einer Praxis tätig waren. Die Befragten glauben, dass nur $7 \%$ der Veranstaltungen, die sich allein aus den Teilnehmergebühren tragen, mit Voreingenommenheit (Bias) belastet sind. Andererseits meinen sie, dass diese Rate auf $46 \%, 80 \%$ oder $86 \%$ steigt, wenn die Fortbildung zu 20\%, $60 \%$ oder $100 \%$ von einem einzelnen Sponsor gefördert wird. Wenn zwei oder mehr konkurrierende Firmen als Sponsoren kooperieren, gehen diese Raten auf $33 \%$, $57 \%$ und $70 \%$ zurück. Zwei von drei Referenten wird Voreingenommenheit unterstellt, wenn sie für ihre Vorträge oder ihre Forschung Geld erhalten. Bei Referenten, die kein Honorar erhalten, wird nur jeder Zwanzigste verdächtigt. Die Kehrseite der Medaille: Nur $17 \%$ der Ärzte fordern den Verzicht auf industrielle Unterstützung bei der Fortbildung und nur $42 \%$ wären bereit, höhere Teilnahmegebühren zu zahlen, um Bias zu eliminieren oder zu mindern.

Kommentar: In den USA tragen Pharmaund Geräteindustrie zu $60 \%$ die Kosten der zertifizierten ärztlichen Fortbildung. Immer wieder wird gefordert, auf diese Art der Unterstützung zu verzichten. Dabei ist allen klar, dass dann die Teilnehmer höhere Kosten aufbringen und auf einige Annehmlichkeiten verzichten müssten. Es ist gut, dass nun auch einmal die Meinung der betroffenen Ärzte gehört wurde.

Die Komplexität des Problems ist offensichtlich: Die Mehrzahl der Ärzte rechnet mit Vorurteilen bei industriegestützter Fortbildung. Trotzdem möchten sich die Ärzte nicht durch höhere Teilnehmergebühren an den Kosten beteiligen, die sie im Übrigen erheblich unterschätzen. Erhebungen in den USA besagen, dass Ärzte derzeit jährlich circa 1.400 Dollar für die CME-Fortbildung ausgeben und dass dieser Betrag bei Verzicht auf industrielle Förderung auf 3.500 Dol-

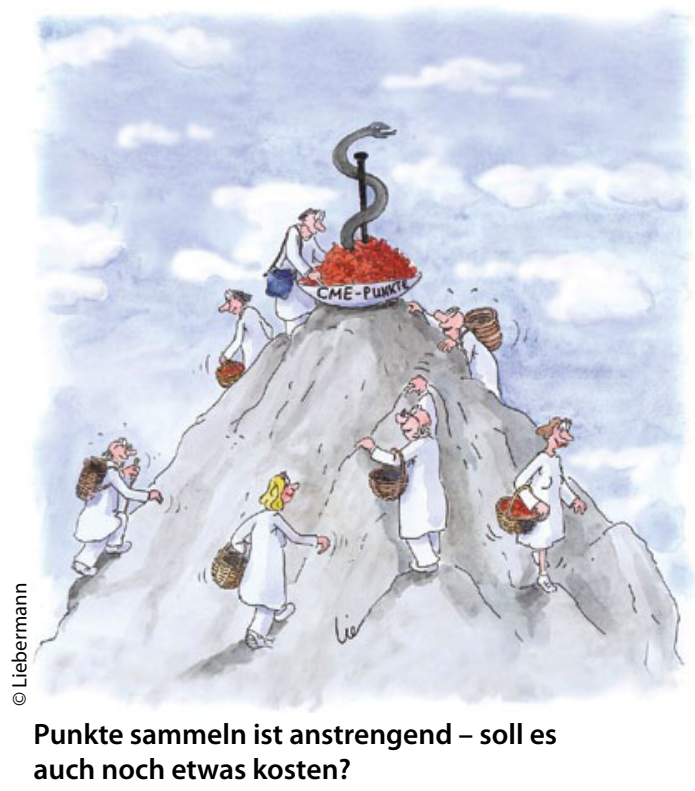

lar ansteigen würde. Wenn Ärztekammern einsprängen, müssten sie - nach Erhebungen aus dem Jahr 2006 in den USA - 15 Milliarden Dollar aufbringen und sicherlich die Beiträge deutlich erhöhen. Soforthilfe in diesem Dilemma: der kritische Verstand der Ärzte und alternative, zertifizierte, audiovisuelle CME-Methoden. Prof. Heinrich Holzgreve

Tabas JA et al.: Clinician attitudes about commercial support of continuing medical education. Arch Intern Med 2011; 171: 840-6 